\title{
FRACTURE RESISTANCE OF CAD/CAM FABRICATED IMPLANT - SUPPORTED ALL - CERAMIC CROWNS CEMENTED ON READY AND CUSTOM MADE ZIRCONIA ABUTMENTS
}

\author{
Hanaa I. Sallam*
}

\begin{abstract}
Statement of the problem: Despite their outstanding esthetic characteristics, the adequacy of implant-supported all-ceramic crowns under occlusal loads in the posterior segment of the jaw remains questionable.
\end{abstract}

Aim of the study: Evaluation of the fracture resistance of different CAD/CAM fabricated implant-supported all-ceramic monolithic posterior crowns cemented on ready and custom made zirconia abutments.

Materials and methods: 30 internal connection titanium dummy implants were embedded in epoxy resin and randomly divided into three groups ( $\mathrm{n}=10$ each) according to the crown material used; Group I: Polycrystalline ceramic (Katana Zirconia), Group II: Hybrid ceramic (Vita Enamic) and Group III: Lithium disilicate glass ceramic (IPS e.max CAD).All crowns were CAD/CAM fabricated as monolithic maxillary right first premolar.In each group, five crowns were cemented on ready made zirconia abutments (subgroup A) while the other five were cemented on custom made zirconia abutments (subgroup B). All samples were thermocycled ( $5^{\circ}$ to $55^{\circ}, 10$ seconds dwell time) then compressively loaded under axial static load till fracture using a universal testing machine with a loadcell of $5 \mathrm{kN}$ at a cross-head speed of $1 \mathrm{~mm} / \mathrm{min}$. The load required to fracture was recorded in Newton and failure modes were visually analyzed. Statistical analyses were performed by Two-way ANOVA and Tukey's post-hoc test. $(\mathrm{P} \leq 0.05)$

Results: Fracture resistance of implant-supported all-ceramic monolithic posterior crowns was statistically significantly affected by the ceramic crown material and abutment type $(\mathrm{P}<0.001)$. Either with ready or custom-made zirconia abutments; zirconia crowns recorded the statistically significantly highest fracture resistance mean value followed by IPS e.max CAD ones while Vita Enamic crowns recorded the lowest values with no statistically significant difference between them and IPS e.max CAD crowns. Zirconia and Vita Enamic crowns cemented on custom made abutments recorded statistically significantly higher mean fracture resistance values than those cemented on ready made one. However, IPS e.max Cad crowns cemented on both abutment types showed statistically insignificant difference. Different failure modes were observed among the tested ceramic crowns without fracture of any abutment.

\footnotetext{
* Associate Professor of Fixed Prosthodontics, Faculty of Oral and Dental Medicine, Cairo University.
} 
Conclusions: All tested implant-supported all-ceramic monolithic posterior crowns cemented on ready and custom made zirconia abutments had the potential to withstand the physiologic occlusal forces in the premolar region with the superiority of the zirconia crowns cemented on custom made zirconia abutments.

KEYWORDS: Dental implants, CAD/CAM, zirconia abutments, monolithic crowns, zirconia, Vita Enamic, IPS e. max CAD, fracture resistance.

\section{INTRODUCTION}

Replacing single missing teeth in any region of the jaw using osseointegrated implants has become a predictable treatment modality with high survival rates. Success depends not only on successful osseointegration and an implant's functional load-bearing capacity, but also on the harmonious integration of a crown into the dental arch. ${ }^{(1,2)}$ Different materials and components were proposed for implant-supported single crowns. Dental abutments traditionally fabricated from titanium because of its well-documented biocompatibility and mechanical properties. ${ }^{(3)}$ Yet, the color of underlying titanium abutments negatively affected the appearance of peri-implant mucosa ${ }^{(4,5)}$ Even when placed subgingivally, a dull gray background may give the soft tissue an unnatural bluish appearance especially under all ceramic crowns. ${ }^{(6)}$ Therefore, for achieving optimal mucogingival esthetics, tooth colored all-ceramic abutments were developed. (7) Currently, Ceramic abutments are fabricated from densely sintered high purity alumina or partially stabilized zirconia. Both materials have improved optical properties, so a more esthetic outcome could be achieved compared to using titanium abutments. ${ }^{(8)}$ Nowadays most implant companies offer prefabricated ceramic abutments that can be prepared in the dental laboratory. ${ }^{(9)}$ Often, prefabricated abutments cannot provide refined morphologic enhancement of dental implant esthetics as they are available in cylindrical form which leaves the emergence profile modifiable only by the final crown. (10) An option toward perfecting the overall esthetic outcome is the use of custom made all ceramic abutments. ${ }^{(11-15)}$ Recent developments in computeraided designing / computer-aided manufacturing (CAD/CAM) technique made it possible to use high strength ceramics (mainly zirconia) to fabricate implant-supported all-ceramic abutments with customized contour that match carefully the clinical situation. ${ }^{(11-16)}$ Lithium disilicate ceramic (E max cad) was also used for custom made implant abutments. ${ }^{(17)}$ The ceramic CAD/CAM abutments combine most of the advantages of stock and cast custom abutments. In addition to its predictable fit and durability, all the prosthesis parameters are modifiable including the emergence profile, finish line thickness and location as well as external contour which results in improved final esthetics of implant supported restoration. ${ }^{(10,18)}$

Implant prosthetic components should exhibit sufficient durability to withstand functional loading without fracture. ${ }^{(10)}$ The combination of a highstrength ceramic abutment and a high-strength allceramic superstructure system would enhance the overall resistance of the restoration as well as its final esthetic, ${ }^{(19)}$ and has been described in the literature in anterior and posterior regions of the jaw ${ }^{(11,13,14,20-30)}$ either in the form of high strength ceramic core to be veneered with a more esthetic ceramic or most recently in the form of monolithic restoration using the CAD/CAM technology. ${ }^{(31)}$ Among the ceramic systems used are glass ceramics ${ }^{(11,20-22,25-27,29)}$, densly sintered Alumina ${ }^{(28)}$, zirconia $^{(14,20,21)}$, feldspathic ceramics $^{(22,23)}$, hybrid ceramics ${ }^{(21,23-26,30)}$, zirconia reinforced lithium silicate. ${ }^{25,26)}$

Several studies were carried out to compare the fracture resistance of different all ceramic crowns 
to evaluate their appropriateness for implant restorations in the posterior region..$^{(20-23,25,26,30)}$ In a study conducted in vitro by Stona etal ${ }^{(22)}$, the fracture resistance for three different groups of CAD/CAM fabrication all ceramic implant supported premolar crowns (feldspathic Vita Mark II, IPS Empress CAD and IPS e max CAD ) was evaluated and compared after cyclic fatigue loading and static loading. They concluded that all tested ceramic materials showed sufficient resistance to withstand normal chewing forces but feldspathic Vita Mark II crowns were inferior to other tested materials. Similarly, Kim et al ${ }^{(20)}$ reported that monolithic CAD/CAM lithium disilicate crowns are applicable to posterior implant supported restorations.

Yttria -stabilized tetragonal zirconia polycrystalline (Y-TZP) is another all ceramic material which recorded high fracture strength values when used by many researchers for construction of implant supported crowns. ${ }^{(20,21)}$ A group of investigators ${ }^{(20)}$ compared the fracture load of mandibular first molar zirconia crowns (zirconia copings veneered by layering or heat pressing) with that of monolithic e max CAD ones. Their results showed that zirconia crowns with heat pressed veneer recorded the highest fracture load among the tested groups. Recently, Kok et $\mathrm{al}^{(21)}$ used ten different ceramic and composite resin materials (among which was zirconia) for CAD/CAM fabrication of implant supported monolithic and veneered molars and compared their initial load to failure. The highest initial load to failure was recorded with the monolithic zirconia crowns.

Unfortunately, under tensile stresses ceramic materials are susceptible to fracture as a result of their brittleness,surface and bulk defects as well as crack propagation under oral function. ${ }^{(32)}$ In order to improve the reliability of ceramics a novel polymer infiltrated ceramic (hybrid ceramic)was developed..$^{(33,34)}$ Due to its low modulus of elasticity, the hybrid material absorb more energy than ceramics and therefore lead to more damping of occlusal forces, as found in earlier study. ${ }^{(35)}$
Many investigations (21,23-26) were designed to study how the new hybrid ceramic material performs within an implant system. Kok et al ${ }^{(21)}$ mentioned that although monolithic ceramic restorations might perform better than composite resin one, Vita Enamic monolithic crown recorded initial load to failure that was higher than the biting force in the posterior region.Similar results were found in a study carried out by Weyhrauch et $\mathrm{al}^{(26)}$ who compared the fracture strength of monolithic all ceramic implant supported premolar crowns on titanium abutments and found that Vita Enamic showed higher fracture strength than the maximum occlusal forces in the premolar area. Additionally, Rosentritt et al ${ }^{(25)}$ compared the fracture resistance (after thermal cycling and mechanical loading) of CAD/CAM fabricated implant supported molar crowns made of Lithium disilicate; E max CAD, resin infiltrated ceramic; Vita Enamic and zirconia reinforced lithium silicate; Celtra Duo. They reported that all restorations were in the range where clinical application seems not restricted, but insertion of a screw channel might reduce stability of individual materials.

From the previous review in relation to the implant restorative material, there remains an open question: which ceramic material would behave better mechanically when cemented on ready and custom made zirconia abutments with different designs? Therefore, this study was conducted to evaluate the fracture resistance of $\mathrm{CAD} /$ CAM fabricated implant-supported monolithic posterior crowns that are cemented on ready and custom made zirconia abutments and constructed of Polycrystalline ceramic (Katana Zirconia), Hybrid ceramic (Vita Enamic) as well as Lithium disilicate glass ceramic (IPS e.max CAD). The null hypotheses of this investigation were that (1) the all ceramic crowns tested would show no difference in their fracture resistance and (2) the abutment type would not affect the fracture resistance of the tested crowns. 


\section{MATERIALS AND METHODS}

\section{Construction of the implant models}

30 internal connection titanium dummy implants (Legacy 1 system, Implant direct, Sybron International, USA) with $3.7 \mathrm{~mm}$ diameter, $13 \mathrm{~mm}$ length and $3.5 \mathrm{~mm}$ platform diameter were used in this study. Transfer copings supplied by the implant manufacturer ( $3.5 \mathrm{~mm}$ platform diameter)were screwed to all implants by the aid of the implant system hex tool to hold the implants during fabrication of the models.Each implant-transfer coping assembly was centrally inserted in a machine milled copper cylinder by the aid of a specially constructed parallelometer to be parallel to the cylinder outer surface. To simulate an osseointegrated implant and because its modulus of elasticity is similar to that of the bone ${ }^{(11,14,22)}$, an epoxy resin material (Kemapoxy 150, CMB International, Egypt) was proportioned and mixed according to the manufacturer instructions then injected in the copper cylinder around the implant up to its first thread to resemble the vertical bone loss around the implant. ${ }^{(11)}$ The sample was left for 24 hours till complete polymerization of the epoxy resin then retrieved from the copper cylinder. This procedure was repeated till completion of the 30 samples. Finally, All transfer copings were unscrewed from the implants.

\section{Study design and samples grouping}

The 30 implant samples were randomly divided into three groups ( $\mathrm{n}=10$ each) according to the crown material used (Table 1); Group I :Yttria -stabilized tetragonal zirconia polycrystalline (Y-TZP) (Katana zirconia), Group II : hybrid ceramic (Vita Enamic) and Group III : Lithium-disilicate glass ceramic (IPS e.max CAD). All crowns were CAD/CAM fabricated in the form of monolithic maxillary right first premolar. In each group, five crowns were cemented on ready made zirconia abutments (subgroup A) while the other five were cemented on custom made zirconia abutments (subgroup B).
All samples were subjected to thermocycling then compressively loaded till fracture and the failure modes were visually analyzed.

\section{Abutments placement}

\section{3.a. Ready made Zirconia abutments}

Five implants in each group received ready made contoured two-piece zirconia abutments with internal connection and gold anodized titanium base (Implant direct, Sybron International, USA).All abutments had standardized dimensions of $3.5 \mathrm{~mm}$ platform diameter, $0.5 \mathrm{~mm}$ chamfer finish line ${ }^{(29)}$ with scalloped pattern ${ }^{(12)}, 7.6 \mathrm{~mm}$ length above the collar height at the buccal side and $6.1 \mathrm{~mm}$ at the lingual side as well as $8^{\circ}$ total convergence angle. Abutments were screwed to implants by titanium screws which were torqued to $30 \mathrm{Ncm}$ according to the manufacturer recommendations using calibrated torque wrench and hex tool (Implant direct, Sybron International, USA). All abutments were reduced in height (1.6 mm length was removed) by a single operator so their final length was $6 \mathrm{~mm}$ above the collar height at the buccal side and $4.5 \mathrm{~mm}$ at the lingual side. This was carried out using zirconia bur block shaping and polishing kit (Implant direct, Sybron International, USA), then the length was checked by a digital caliber. Finally, all abutments were polished with the polishing tools of the kit.

\section{3.b. Custom made Zirconia abutments (hybrid abutment)}

The other five implants in each group received custom made zirconia abutment after their fabrication. Each abutment consisted of a titanium base (with $3.5 \mathrm{~mm}$ platform diameter) compatible with the implant system (Ti base, Osteoseal Co.USA) that was adhesively luted to a CAD/CAM fabricated zirconia structure. The zirconia structure was designed by the DOW CAD software (dental wings Inc. Montreal, Canada) in the form of anatomically prepared maxillary first premolar (to receive all- 
TABLE (1) All-ceramic crown materials used in the study

\begin{tabular}{|c|c|c|}
\hline Material & Description, properties \& composition & Manufacturer \\
\hline $\begin{array}{l}\text { Yttria -stabilized } \\
\text { tetragonal zirconia } \\
\text { polycrystalline } \\
\text { (Zirconia ) } \\
\text { (group I) }\end{array}$ & 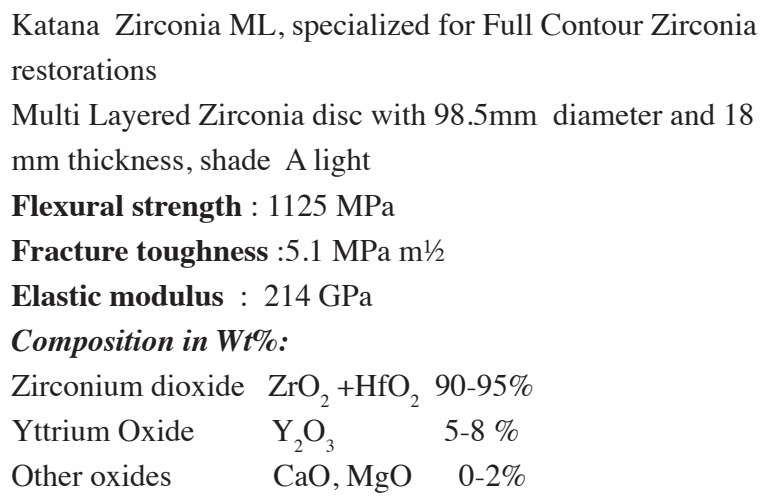 & $\begin{array}{c}\text { Kuraray Noritake Dental Inc. } \\
\text { Japan }\end{array}$ \\
\hline $\begin{array}{c}\text { hybrid ceramic } \\
\text { (Vita Enamic) } \\
\text { (group II) }\end{array}$ & 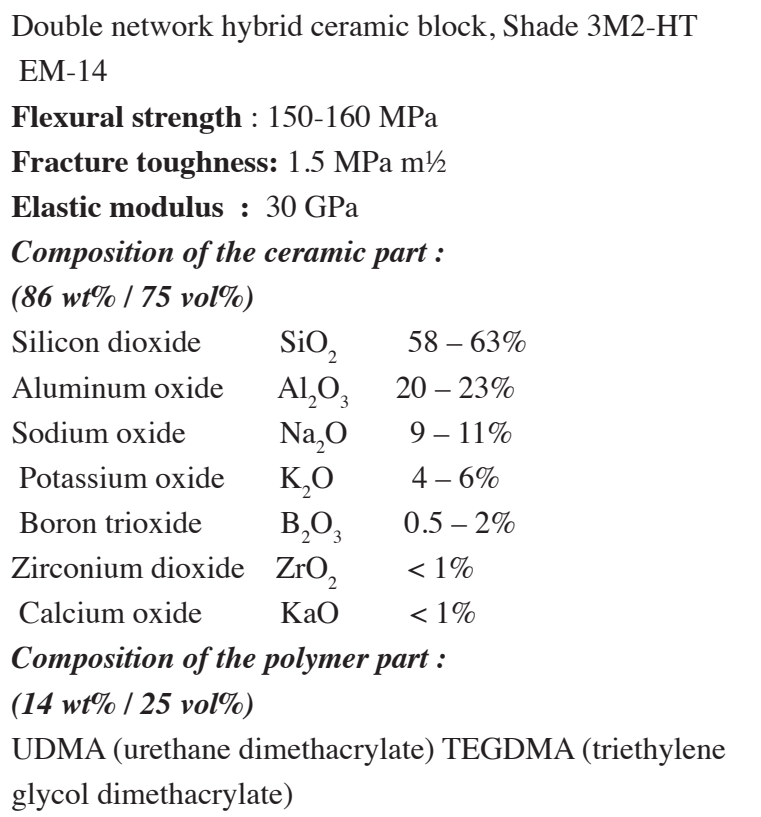 & $\begin{array}{l}\text { VITA Zahnfabrik } \\
\text { Germany }\end{array}$ \\
\hline $\begin{array}{c}\text { Lithium-disilicate glass } \\
\text { ceramic } \\
\text { (IPS e. max CAD) } \\
\text { (group III) }\end{array}$ & 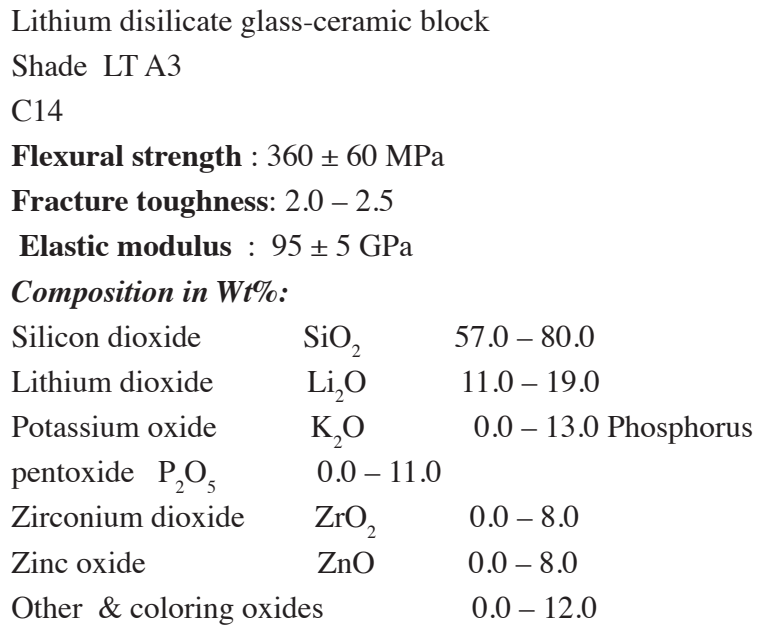 & $\begin{array}{c}\text { Ivoclar Vivadent } \\
\text { Schaan, Liechtenstein }\end{array}$ \\
\hline
\end{tabular}


ceramic crown) with $6 \mathrm{~mm}$ occlusocervical length above the collar height in all surfaces, $1 \mathrm{~mm}$ deep chamfer finish line with even pattern and $12^{\circ}$ total convergence angle as recommended by the ceramic manufacturers preparation guidelines ${ }^{(36)}$. This design was standardized for the 15 custom made abutments used in this study. The designed abutments were milled from Katana Zirconia HT disc ( Kuraray Noritake Dental Inc, Japan) using a 5 axis milling machine (SHERA eco-mill 5 axis, Shera, Germany) then sintered in a furnace (Naber therm HT CT, Shera, Germany) at $1500^{\circ} \mathrm{C}$ for 7 hours as recommended by the manufacturer. The sintered zirconia structure and the titanium base were prepared for adhesive luting by covering the outer surface of the ceramic structure as well as the screw access hole and the emergence profile of the titanium base by modelling wax (Cavex Holland $\mathrm{BV}$, Netherlands)to be protected during the air born particle abrasion procedure which was carried out to the bonding areas of the two components by $50 \mu \mathrm{m}$ $\mathrm{Al}_{2} \mathrm{O}_{3}$ particles at 1 bar pressure, then the wax was removed and the components were ultrasonically cleaned in distilled water and dried with oil free air spray. The abraded bonding areas of the two components were conditioned with a universal primer (Monobond Plus, Ivoclar Vivadent, Schaan, Liechtenstein) which was allowed to react for 60 seconds then air dispersed. The surface treated titanium base was screwed to an implant analogue (to be able to receive the ceramic structure) and a thin layer of self curing automix opaque adhesive resin cement (Multilink Hybrid Abutment HO 0, Ivoclar Vivadent, Schaan, Liechtenstein) was applied to the bonding areas of the titanium base and the zirconia structure that was lightly pressed onto the titanium base. Excess cement at the cement joint and at the screw channel was removed by microbrush (Microbrush International, UAS) and glycerin gel (Liquid strip, IvoclarVivadent, Schaan, Liechtenstein) was applied on the cement joint (to prevent the formation of oxygen inhibited layer) and left for 7 minutes till complete polymerization of the cement following the manufacturer's instructions then rinsed with water spray. The cement joint was polished with rubber polishers (Dedeco International Inc, USA) at low speed and finally, the custom made abutment (hybrid abutment) was unscrewed from the implant analogue. Each custom made zirconia abutment was screwed to its corresponding implant by the aid of the titanium screw of the titanium base and torqued to $30 \mathrm{Ncm}$ as recommended by the manufacturer using the calibrated torque wrench and hex tool (Implant direct, Sybron International, USA).

\section{CAD/CAM fabrication of all-ceramic mono- lithic crowns}

The different types of all-ceramic monolithic posterior crowns used in this study were CAD/CAM fabricated according to the following standardized protocol:

\section{4.a. Optical impression of all abutments:}

For the optical impression, ready and custom made abutments were sprayed with titanium dioxide powder (Cerec. Optispray, Sirona Dental Systems GmbH, Bensheim, Germany)then scanned by In Eos scanner (Sirona Dental Systems GmbH, Bensheim, Germany) and the resultant 3D images were saved on the computer.

\section{4.b. Virtual designing of the monolithic crowns:}

By the aid of the in Lab 4.3CAD software (Sirona Dental Systems GmbH, Bensheim, Germany),all crowns were individually designed onto their corresponding virtual 3D abutment models. Each crown was designed in the form of fully contoured monolithic maxillary right first premolar with 1.5$2 \mathrm{~mm}$ ceramic thickness at the occlusal surface (1.5 $\mathrm{mm}$ at the central groove, $2 \mathrm{~mm}$ at the tip of the cusps) and $80 \mathrm{~m} \mu$ spacer following the parameters needed for ceramic restoration. ${ }^{(27)}$ This design was adopted to all tested crowns. Exceptionally for 
zirconia crowns, this design was enlarged by $25 \%$ to compensate for the zirconia sintering shrinkage.

\section{4.c. Crowns milling procedure:}

In order to start the milling procedure data including the size of the ceramic disc or the block was loaded in the cerec software. The in Lab 15 CAM software was used for the milling procedure which was carried out in the in Lab MC x5 milling machine (Sirona Dental Systems GmbH, Bensheim, Germany).

After completion of the milling procedure, the followings were carried out:

The milled zirconia crowns were sintered in a furnace (in Fire HTC speed, Sirona) Dental Systems GmbH, Bensheim, Germany) for 7 hours at $1500^{\circ} \mathrm{C}$ following the manufacturer instructions. The sintered crowns were polished using diamond polishing system specialized for zirconia (EVE DIACERA Set HP 321, EVE Ernst Vetter GmbH, Germany)

The milled Vita Enamic crowns were polished with the pink polishers of the Vita Enamic polishing kit (VITA Zahnfabrik, Germany) followed by the grey polishers of the kit.

The milled IPS e max CAD crowns were polished while they were in the precrystallized blue state with a diamond polishing system for silicate ceramics (EVE DIAPRO Set HP 360, EVE Ernst Vetter GmbH, Germany) then ultrasonically cleaned in distilled water for two minutes. After that, the cleaned crowns were subjected to crystallization cycle in the Programat P310 furnace (Ivoclar Vivadent, Schaan, Liechtenstein) at $850^{\circ} \mathrm{C}$ for a total firing time of 25 minutes according to the manufacturer recommendations.

After finishing of the previous procedures, all crowns were ultrasonically cleaned in distilled water for two minutes and dried by oil free air spray.

\section{Surface treatments and cementation of the crowns}

Prior to their cementation onto their corresponding abutments, the different crowns were subjected to their manufacturer recommended surface treatments as follows: the intaglio surfaces of the zirconia crowns were air born particle abraded by $50 \mu \mathrm{m} \mathrm{Al}_{2} \mathrm{O}_{3}$ particles at 1 bar pressure then ultrasonically cleaned and air dried. The fitting surfaces of Vita Enamic and IPS e max CAD crowns were subjected to acid etching by hydrofluoric acid 5\% (IPS Ceramic Etching Gel, Ivoclar Vivadent) for 60 seconds for Vita Enamic crowns and 20 seconds for IPS e max CAD ones, then thoroughly rinsed with water and air dried. A ceramic primer (Clearfil Ceramic Primer, Kuraray, USA) was applied to the treated fitting surfaces of all crowns (zirconia, Vita Enamic and IPS e max CAD) and allowed to react for 60 seconds then air dispersed.

The screw access holes of ready and custom made abutments of all subgroups were sealed with cotton pellets and temporary filling material (Cavit, 3M ESPE, USA). A specially constructed cementing device was used to standardize the cementing procedure for all samples.An automix dual cure self adhesive resin cement (Panavia SA cement Plus, white, Kuraray, USA) was applied to the treated fitting surfaces of all crowns. Each crown was immediately seated onto its corresponding abutment under finger pressure then placed in the cementing device under constant axial load of $5 \mathrm{Kg} .{ }^{(37)}$ Excess cement at the margins was light cured for two seconds by LED curing unit (LED curing unit LY-B 200, LIANG YA Dental, China) then removed by dental explorer.The cement was photopolymerized for 10 seconds /surface by the LED curing unit on all surfaces of the crown. All samples were kept at $100 \%$ humidity at $37^{\circ} \mathrm{C}$ for 24 hours.

\section{Thermal cycling of the samples}

After the 24 hours storage period, samples were subjected to thermocycling (Robota thermocycle; BILGE, Turkey) between two water bathes 
$\left(5^{\circ} \mathrm{C}\right.$ and $\left.55^{\circ} \mathrm{C}\right)$ with 10 seconds dwelling time in each water bath. The number of cycles carried out was 500 cycle. ${ }^{(38)}$

\section{Fracture Resistance testing}

Each implant -abutment-crown complex was individually mounted on a computer controlled materials testing machine (Model 3345; Instron Industrial Products, Norwood, MA, USA) with a loadcell of $5 \mathrm{kN}$ and data were recorded using computer software (Instron ${ }^{\circledR}$ Bluehill Lite Software). Samples were secured to the lower fixed compartment of the testing machine then compressive load was applied on the occlusal surface of each crown by a metallic rod with spherical tip (5.8mm diameter, contacting the buccal and palatal cuspal inclines) attached to the upper movable compartment of testing machine and traveling at a cross-head speed of $1 \mathrm{~mm} / \mathrm{min}$. A tin foil with $1 \mathrm{~mm}$ thickness was placed between the load applicator and the occlusal surface of the crown to achieve homogenous stress distribution and to minimize the transmission of local force peaks. The load at fracture was recorded in Newton.

\section{Failure mode analysis}

Each fractured sample was visually examined with a magnifying lens and the location and mode of failure for each sample was recorded. Additionally, mobility of the abutment and any plastic deformation of the implant neck were recorded. The failure modes were categorized according to Mühlemann et al ${ }^{(11)}$ into: 1-Partial or catastrophic fracture of abutment and/or crown, 2- visible crack of abutment and/or crown and 3-plastic deformation of components (implant, abutment, screw),

\section{Statistical analysis}

Two-way ANOVA was used to study the effect of crown material, abutment type and their interactions on mean fracture resistance. Tukey's post-hoc test was used for pair-wise comparisons when ANOVA test is significant. The significance level was set at $\mathrm{P} \leq 0.05$. Statistical analysis was performed with IBM (IBM Corporation, NY, USA) SPSS Statistics Version 20 for Windows (SPSS, Inc., IBM Company).

\section{RESULTS}

\section{Statistical analysis results}

Data were presented as mean, median, standard deviation (SD), range (Minimum - Maximum) and 95\% Confidence interval $(95 \% \mathrm{CI})$ for the mean values. Data were explored for normality by checking the data distribution and using KolmogorovSmirnov and Shapiro-Wilk tests. Fracture resistance data showed parametric distribution(Table 2).

TABLE (2) Descriptive statistics for fracture resistance values of the different groups

\begin{tabular}{|c|c|c|c|c|c|c|c|c|}
\hline \multirow{2}{*}{$\begin{array}{l}\text { Crown } \\
\text { material }\end{array}$} & \multirow{2}{*}{ Abutment type } & \multirow{2}{*}{ Mean } & \multirow{2}{*}{ SD } & \multirow{2}{*}{ Median } & \multirow{2}{*}{ Minimum } & \multirow{2}{*}{ Maximum } & \multicolumn{2}{|c|}{$95 \% \mathrm{CI}$} \\
\hline & & & & & & & Lower bound & Upper bound \\
\hline \multirow{2}{*}{ Zirconia } & Ready made & 957.9 & 56.8 & 962.5 & 845.8 & 1025.4 & 908.1 & 1836.7 \\
\hline & Custom made & 1304.3 & 112.9 & 1286.5 & 990.5 & 1402.8 & 1205.3 & 2475.4 \\
\hline \multirow{2}{*}{$\begin{array}{c}\text { Vita } \\
\text { Enamic }\end{array}$} & Ready made & 446.4 & 49.1 & 450.1 & 371.4 & 556.8 & 403.4 & 839.7 \\
\hline & Custom made & 604.4 & 78.5 & 602.5 & 499.5 & 715.7 & 535.6 & 1128.3 \\
\hline \multirow{2}{*}{$\begin{array}{l}\text { IPS e.max } \\
\text { CAD }\end{array}$} & Ready made & 685.0 & 79.0 & 688.4 & 591.2 & 720.0 & 615.8 & 1285.9 \\
\hline & Custom made & 771.9 & 158.5 & 765.8 & 628.7 & 814.4 & 633.0 & 1399.1 \\
\hline
\end{tabular}


Fracture resistance of implant-supported all-ceramic monolithic posterior crowns was statistically significantly affected by the crown material as indicated by two way ANOVA test $(\mathrm{P}<0.001)$ regardless of abutment type. Zirconia crowns recorded the statistically significantly highest fracture resistance mean value $(1131.1 \pm 88.5)$ followed by IPs e.max CAD crowns $(728.4 \pm 158.9)$ while Vita Enamic ones recorded the lowest values $(525.4 \pm 121.6)$. Tukey's pair-wise post-hoc test showed non-significant difference between IPs e.max CAD and Vita Enamic crowns (Table 3).

TABLE (3) Comparison of fracture resistance results $($ Mean \pm SD) for different crown materials regardless of abutment type

\begin{tabular}{ccccccc}
\hline \multicolumn{2}{c}{ Zirconia } & \multicolumn{2}{c}{ Vita Enamic } & \multicolumn{2}{c}{ IPs e.max CAD } & \multirow{2}{*}{$\boldsymbol{P}$-value } \\
\cline { 1 - 4 } Mean & SD & Mean & SD & Mean & SD & \\
\hline $1131.1^{\mathrm{A}}$ & 88.5 & $525.4^{\mathrm{B}}$ & 121.6 & $728.4^{\mathrm{B}}$ & 158.9 & $<0.001^{*}$ \\
\hline
\end{tabular}

*: Significant at $P \leq 0.05$, Different superscripts indicate statistically significant difference

Similarly, the fracture resistance of implantsupported all-ceramic monolithic posterior crowns was statistically significantly affected by the abutment type as indicated by two way ANOVA test $(\mathrm{P}<0.001)$ regardless of the crown material. It was found that crowns cemented on custom made zirconia abutments recorded statistically significantly higher mean fracture resistance values (893.5 \pm 211.6$)$ than those cemented on ready made ones $(696.4 \pm 171.3)$ (Table 4$)$.
TABLE (4) Comparison of fracture resistance results (Mean \pm SD) for different abutment types regardless of crown material

\begin{tabular}{lcccc}
\hline \multicolumn{2}{c}{ Ready made } & \multicolumn{2}{c}{ Custom made } & \multirow{P}{c}{-value } \\
\cline { 1 - 3 } Mean & SD & Mean & SD & \\
\hline 696.4 & 171.3 & 893.5 & 211.6 & $<0.001^{*}$ \\
\hline
\end{tabular}

*: Significant at $P \leq 0.05$

\section{Effect of interaction between crown material and abutment type}

Comparison between crown materials, either with ready or custom-made abutments; it was found that zirconia crowns recorded the statistically significantly highest fracture resistance mean value followed by IPs e.max CAD ones while Vita Enamic superstructures recorded the lowest value. There was no statistically significant difference between Vita Enamic and IPs e.max CAD groups for both abutment types (Table 5, Figure1).

Comparison between abutment types, either with Zirconia or Vita Enamic crowns; it was found that crowns cemented on custom made zirconia abutments recorded statistically significantly higher mean fracture resistance value than those cemented on ready made ones, while with IPs e.max CAD; it was found that there was no statistically significant difference between the two abutment types (Table 5, Figure1).

TABLE (5) Comparison of fracture resistance results (Mean \pm SD) for different implant-supported allceramic monolithic posterior crowns cemented on ready and custom-made zirconia abutments

\begin{tabular}{|c|c|c|c|c|c|c|c|}
\hline & \multicolumn{2}{|c|}{ Zirconia } & \multicolumn{2}{|c|}{ Vita Enamic } & \multicolumn{2}{|c|}{ IPs e.max CAD } & \multirow{2}{*}{$\begin{array}{c}P \text {-value } \\
\text { (Between crowns) }\end{array}$} \\
\hline & Mean & SD & Mean & SD & Mean & SD & \\
\hline Ready made & $957.9^{\mathrm{A}}$ & 56.8 & $446.4^{\text {в }}$ & 49.1 & $685.0^{\mathrm{B}}$ & 79.0 & $<0.001 *$ \\
\hline Custom made & $1304.3^{\mathrm{A}}$ & 112.9 & $604.4^{\text {в }}$ & 78.5 & $771.9^{\mathrm{B}}$ & 158.5 & $0.002 *$ \\
\hline $\begin{array}{c}P \text {-value } \\
\text { (Between abutments) }\end{array}$ & \multicolumn{2}{|c|}{$0.034 *$} & \multicolumn{2}{|c|}{$0.042 *$} & \multicolumn{2}{|c|}{0.327} & \\
\hline
\end{tabular}

\footnotetext{
*: Significant at $P \leq 0.05$, Different superscripts in the same row indicate statistically significant difference
} 


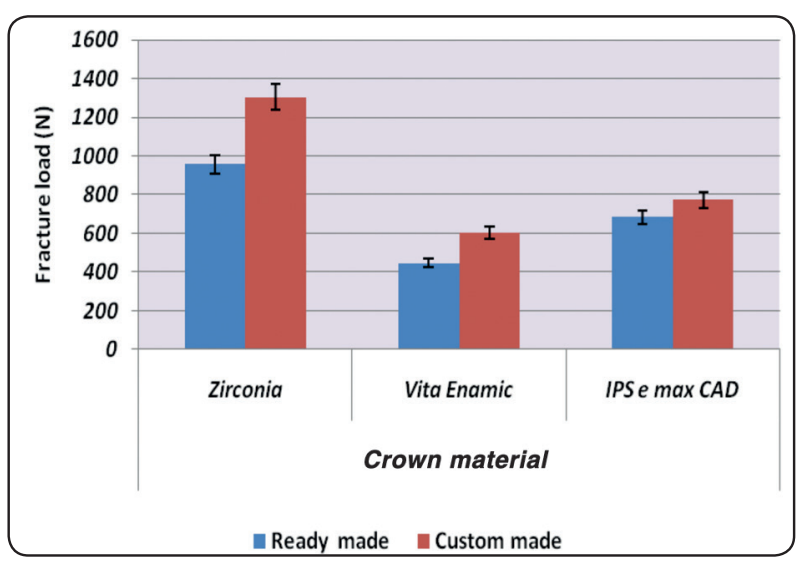

Fig. (1) Bar chart comparing the fracture resistance results (Mean \pm SD) of different implant-supported allceramic monolithic posterior crowns cemented on ready and custom-made zirconia abutments.

\section{Failure mode analysis results}

After photographing of the cracked and fractured crowns, the fragments of the crowns (which were still attached to ready and custom made abutments) were removed from the underlying zirconia abutments to allow for abutment examination.Visual examination of each abutment/crown fragments revealed that most of the cement remnants were predominantly attached to the crown fragments and not to the underlying ready or custom made zirconia abutments which did not exhibit any crack lines or actual fractures after being visually inspected with the magnifying lens.Additionally, no mobility was manifested with any abutment and the implant neck of all samples did not show plastic deformation.

\section{Implant-supported all-ceramic monolithic posteri- or crowns cemented on ready made zirconia abut- ments (Figure $2 a, b, c$ )}

Zirconia crowns showed catastrophic fracture splitting it vertically,just beside the central developmental groove, into two parts. The short palatal half in all samples was detached from the abutments while the longer buccal one remained attached to it. Additionally, in the representative sample (Figure 2, a) an incomplete fracture line was extended from the central groove toward the buccal cusp along the proximobuccal supplemental groove of the triangular fossa.

Vita Enamic crowns exhibited visible crack line near the central developmental groove toward the palatal side and extended transversely from one proximal side to the other. (Figure 2,b )

IPs $\mathrm{E}$ max CAD crowns showed catastrophic fracture of the crowns, the fracture line located occlusally at the central developmental groove and extended mesiodistally till the finish line area. Furthermore, another mid palatal longitudinal fracture line was manifested splitting the functional palatal cusp and the short palatal surface into two fragments. Similar to zirconia crowns, the longer buccal half remained attached to the abutments. (Figure 2,c )

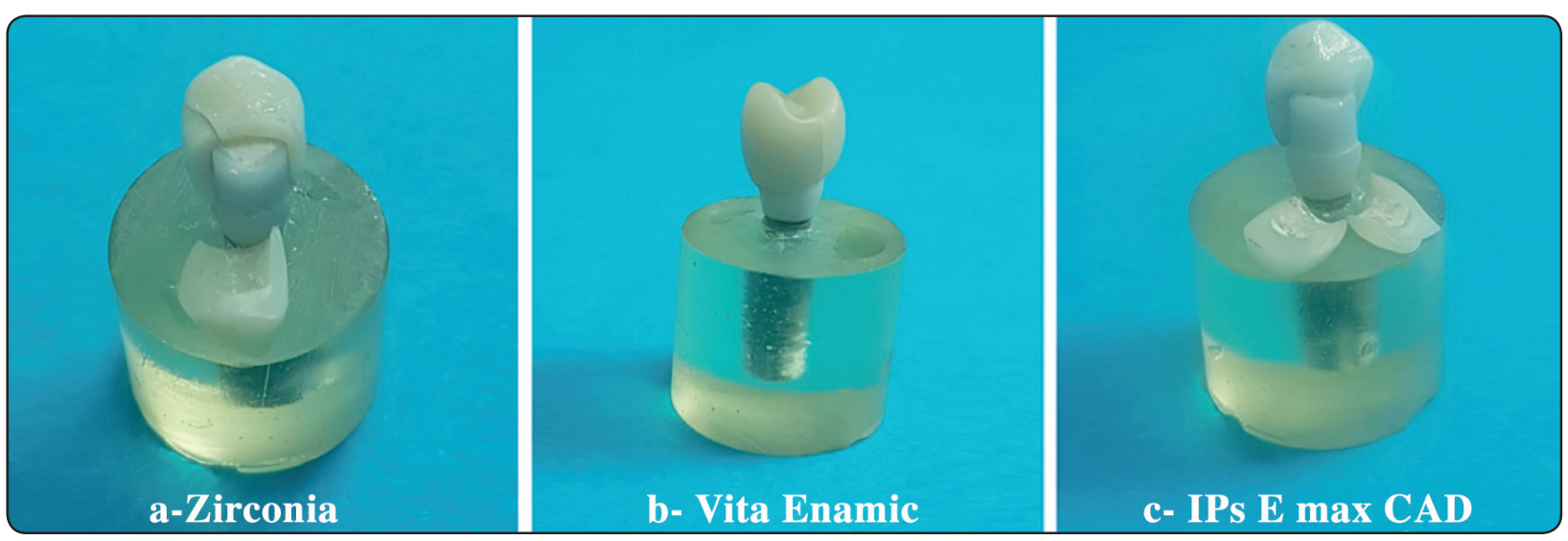

Fig. (2) Representative samples of fractured all-ceramic crowns cemented on ready made abutments 


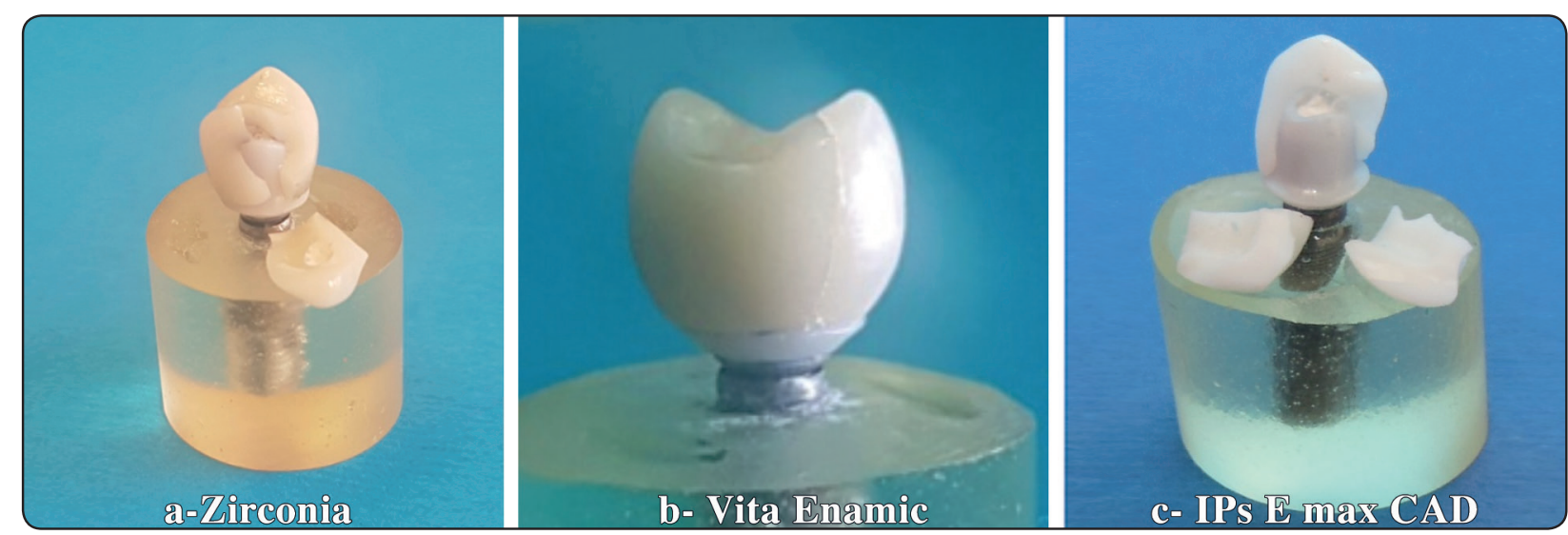

Fig. (3) Representative samples of fractured all-ceramic crowns cemented on custom made abutments

Implant-supported all-ceramic monolithic posterior crowns cemented on custom made zirconia abutments (Figure $3 a, b, c)$

Zirconia crowns representative sample exhibited crescent shape catastrophic fracture in the palatal surface extending from the cusp tip to the thinnest area of crown near its margin. The fracture occurred occlusally in the cusp tip just above the palatal cusp tip of the zirconia abutment. (Figure $3, \mathrm{a}$ )

Vita Enamic crowns cemented on custom made abutments exhibited similar fracture pattern to those cemented on ready made abutments where a visible crack line was extended midway between the central developmental groove and the palatal cusp tip and transversely from one proximal side to the other.(Figure 3,b )

IPs E max CAD crowns showed catastrophic fracture of the crown splitting it into three fragments similar to those cemented on ready made abutments (Figure 3, c )

\section{DISCUSSION}

Implant-supported crowns are commonly used to replace missing teeth. These restorations have a good clinical survival rate and long-term patient satisfaction. ${ }^{(1,2)}$ Abutments play a key role in fitting prosthesis onto dental implants and they are needed to create an appropriate emergence profile.(17) Until today, titanium abutments are considered the 'gold-standard' for longevity of implant-borne reconstructions in all regions of the jaw, unfortunately, they may impair the esthetic result of implant reconstructions. ${ }^{(6)}$ As an alternative ceramic abutments made out of the high-strength ceramics alumina and zirconia can be used. (7) Partially stabilized zirconia shows superior properties to densely sintered high purity alumina due to such microstructural differences as higher density, smaller particle size and their polymorphic mechanism against flow propagation. (9) Many authors reported that all ceramic abutments made of alumina had unfavorable behavior after aging and possessed less favorable properties than zirconia and titanium abutments. ${ }^{(39)}$ Yildrim et al ${ }^{(40)}$ concluded that fracture resistance in zirconia abutment group was more than twice that in alumina group. Additionally, zirconia abutments had a cumulative survival rate of $100 \%$ after observation periods between 4 and 6 years ${ }^{(6,41)}$. In a randomized controlled clinical trial of customized zirconia and titanium implant abutments for singletooth implants in canine and posterior regions, Zembic et $\mathrm{al}^{(42)}$ reported that at 3 years, zirconia and titanium abutments exhibited same survival and technical, biological and esthetical outcomes. Because of the increased mechanical strength and survival rate, it has been suggested to use zirconia instead of alumina as implant abutment 
material ${ }^{(9,39)}$, hence,zirconia was the abutment material of choice in this study.

Most implant companies supply prefabricated ceramic abutments. These abutments are readily available, economical, widely used and its height, width of the finish line and the axial walls can be easily modified manually by the technician or the dentist to accommodate a full coverage restoration. However, their contours are rarely anatomic and do not support the surrounding soft tissues making managing the emergence profile of an implant restoration difficult..$^{(9,10)}$ The initial types of prefabricated all ceramic abutments was totally made of zirconia including the connection part with the implant. With this type of abutments, it has been argued that the ceramo-metal interface (the interface between all-ceramic abutments and titanium implants) is prone to wear and abrasion of the metallic part. ${ }^{(43)}$ Rounding of the corners of the implant external hexagon as a consequence of seating and reseating of ceramic abutments during the fabrication process has been observed. ${ }^{(44)}$ Moreover, all-ceramic abutments cannot be machined to the same degree of precision as metal abutments. An imprecise fit between abutment and implant can lead to screw loosening and other clinical problems such as bone loss due to subsequent microbial infection. ${ }^{(7)}$ To overcome the wear problem at the interface between all-ceramic abutment and titanium implant, an all ceramic abutment in which zirconia is sintered onto titanium base that covers the implant platform and hexagon had been developed. ${ }^{(45,46)}$ Accordingly, ready made zirconia abutment with titanium base was selected in the present study.

A significant advancement in computer-aided designing and computer-aided manufacturing (CAD/CAM) technology has shortened a series of laboratory and clinical steps for rehabilitating patients' dentitions with dental implants. Through the use of this technology, professionals can design and manufacture custom esthetic abutments and all-ceramic crowns in short time and with minimal human intervention, therefore, controls the quality and reduces the defects. ${ }^{(15,16)}$

CAD/CAM custom made implant abutments are increasingly applied for the fabrication of implantborne reconstructions aimed at imitating the natural situation. These abutments are individually shaped according to the anatomical needs of the respective implant site. ${ }^{(11-15)}$ The wear problem occurring at the implant/ceramic interface is solved by the custom made hybrid design in which the zirconia part is adhesively bonded to a titanium base so combines the best of the two worlds. ${ }^{(17)}$ Thus, custom made zirconia hybrid abutment was fabricated in this study.

For fabrication of all ceramic implant crown, zirconia abutments require shoulder or chamfer finish line as mentioned by Sannino et al ${ }^{(47)}$ who reported that chamfer finish line configuration was found to minimize the localized stress as indicated by a 3D finite element analysis than the shoulder one, thus chamfer finish line was selected in the present study. The abutments finish line thicknesses were thinner than those with the natural teethsuch limited preparations may be feasible without restraining the esthetic performance due to the favorable color of the underlying zirconia abutment. ${ }^{(29)}$

The material of choice for implant-supported restorations is affected by esthetic requirements and type of abutment. All-ceramic crowns are better to use over ceramic abutments because they allow for better aesthetics. ${ }^{(48)}$ Regarding a 5-year clinical data, single implant all-ceramic crowns over zirconia abutments showed estimated survival and failure rates corresponded to that of metal ceramic ones supported by metal abutments. ${ }^{(49)}$ Consequently, all ceramic materials were selected in the present study for construction of the implant supported crowns.

The selected ceramic materials belong to three different ceramic families as categorized by Gracis et al (50) who classified the ceramic material according to whether a glass-matrix phase is present (glass-matrix ceramics) or absent (polycrystalline 
ceramics) or whether the material contains an organic matrix highly filled with ceramic particles (resin-matrix ceramics). IPS e max CAD belongs to glass-matrix ceramics and characterized by improved physical properties and translucency due to the high concentration of refined lithium disilicate crystals. ${ }^{(50,51)}$ Katana zirconia ML belongs to polycrystalline ceramics which is a very strong and tough material that is difficult to crack compared to less dense and irregular network found in glasses. Katana zirconia ML is a multi-coloured zirconia block with four layers of color that have different light transmittance capabilities, this might therefore be useful for enhancing the aesthetic appearance of full-contour zirconia restorations made from this material. Partially sintered zirconia blocks were selected in this study as the CAM processing with the softer presintered material not only shortens the milling time but also reduces the wear of the milling tools. ${ }^{(51,52)}$

Vita Enamic belongs to resin-matrix ceramics; the material combines the properties of ceramic and polymer.It consists of a hybrid structure with two interpenetrating networks of ceramic and polymer (Table 1) and it's modulus of elasticity resembling that of natural human dentin. The most remarkable property is the good machinability of the material which takes the leading position among all blocks used to date. ${ }^{(33,34,50)}$

Additionally, the ceramic crown materials were chosen to have different modulus of elasticity (Table 1) as some authors reported that the type of material used for the prosthesis supported by the titanium implant could affect occlusal load ${ }^{(53)}$. Many investigators recommended resilient occlusal material to reduce the forces exerted on implants. ${ }^{(53,54)}$ Menini et al ${ }^{(55)}$ studied the shock absorption capacity of restorative materials for dental implant prostheses and concluded that composite and acrylic resin crowns were more able to absorb shock from occlusal forces than crowns made of zirconia, glass ceramic and gold alloy.
All implant supported crowns tested in this study were fabricated in the form of monolithic crowns as carried out by many authors. ${ }^{(20-27,30)}$ The most frequent clinical complication with zirconia-based crowns was chipping of the veneering porcelain. Fabrication of monolithic full-contour zirconia crown is an alternative that might avoid chipping of veneering. ${ }^{(56)}$ Beuer et $\mathrm{al}^{(57)}$ showed in a laboratory study that anatomic contoured zirconia crowns demonstrated higher resistance to static loading tests than veneered zirconia ones. Additionally, fabrication procedure is simplified for monolithic IPS e max cad and Vita Enamic crowns which showed good results in laboratory studies. ${ }^{(20-22,25,26)}$

Following many researchers (12,15,20-23,26,27), implant-supported all ceramic crowns in this study were cement retained to the underlying abutments as they are simpler to fabricate so decreasing possible laboratory complications. Additionally, Nogueira et $\mathrm{al}^{(14)}$ reported that ceramic crowns cemented onto customized zirconia abutments offered greater fracture resistance than customized screw retained crowns.

Wolf et al ${ }^{(58)}$ declared that esthetic ceramic CAD/ CAM molar implant crowns gained high strength with adhesive cements on both titanium and zirconia implant abutments compared to non adhesive cementation. Therefore, the ceramic crowns in this study were cemented to ready and custom made zirconia abutments using adhesive resin cement as performed by a group of researchers. ${ }^{(11,12,15,20-23,26,27,39)}$

Exposure to water was found to affect the mechanical properties of all ceramic restorations. ${ }^{(59)}$ Furthermore, temperature changes led slow flaw propagation. ${ }^{(60)}$ Thus, all samples of this study were subjected to thermocycling to more closely simulate the clinical situation as implemented by many authors. ${ }^{(11,15,26,33)}$

This study was not only a test of the all ceramic crown materials but rather an investigation of various implant components (implant, abutment and crown) functioning together as a system. The first 
null hypothesis of this study which stated that the all ceramic crowns tested would show no difference in their fracture resistance was partly rejected. The results showed that zirconia crowns recorded the statistically significantly highest fracture resistance mean value, followed by IPs e.max CAD crowns, while Vita Enamic ones recorded the lowest values and the difference between IPs e.max CAD and Vita Enamic crowns was statistically nonsignificant, regardless of the abutment type (Table $3)$. The influence of the type of ceramic on the fracture resistance of implant supported crowns was confirmed earlier. ${ }^{(22)}$ The results of the present study were in accordance with those of Kok et al ${ }^{(21)}$ who examined the mechanical performance of different implant-supported posterior crowns and found that among the tested materials, anatomic contour zirconia crowns had the heights initial load to failure,followed by IPS e max CAD then Vita Enamic. The results were also in agreement with those of Kim et al ${ }^{(20)}$ who reported that implant supported posterior crowns made of zirconia (zirconia core with heat pressed veneer) had significantly higher fracture load compared to IPS e max CAD crowns. On the other hand,the results were contradicting those of Rosentritt et al ${ }^{(25)}$ and Weyhrauch et al ${ }^{(26)}$ who tested the fracture resistance of several CAD/CAM fabricated all ceramic implant supported posterior crowns and found that IPS e max CAD crowns registered statistically significant higher fracture resistance values than Vita Enamic crowns. Possibly, the difference with Rosentritt et $\mathrm{al}^{(25)}$ results may be linked to the methodology as they used screw and cement retained crowns which may affect the results. Whereas, Weyhrauch et al ${ }^{(26)}$ cemented their all ceramic crowns on titanium abutments.

The superior fracture resistance of zirconia crowns on ready and custom made abutments used in this study may be attributed to its metastable tetragonal crystalline structure at room temperature which are densely packed, resulting in a very strong and tough material that is difficult to crack compared to less dense and irregular network found in glasses. ${ }^{(51,61,62)}$ This structure represents an efficient mechanism against flaw propagation. ${ }^{(61)}$ Also, there was a trend to a correlation between in vitro performance as well as fracture results and the individual material properties. ${ }^{(25)}$ Zirconia ceramics exhibit the highest flexural strength and fracture toughness of all dental ceramics currently available(Table 1). ${ }^{(31)}$

IPS e max CAD crowns on both abutment types performed second best (but the difference with Vita Enamic crowns was not statistically significant). This may be linked to its chemical composition and fabrication technique as a block of IPS e.max $\mathrm{CAD}$ is milled at an intermediate stage, during which lithium metasilicate (which corresponds to $40 \%$ of 0.2 to $1.0 \mu \mathrm{m}$ platelet-shaped crystals by volume)is precipitated. In this phase, the material exhibits a bluish color and little chemical durability. Through a thermal crystallization process at $850^{\circ} \mathrm{C}$, the lithium metasilicate is transformed into a lithium disilicate, which corresponds to $70 \%$ by volume of fine-grain crystals, which provides mechanical strength and optical properties of glass ceramics. ${ }^{(63)}$ Furthermore, with subsequent crystallization, flexural strength increases and induced flaws are expected to be reduced, which may lead to a higher resistance to fracture. ${ }^{(25)}$

Vita Enamic crowns on both abutments used recorded the lowest fracture resistance among the tested ceramic crowns. As would be expected, hybrid ceramics are not as strong as ceramics, ${ }^{(31)}$ Vita Enamic is based on a network structure made of aluminum oxide-enriched, fine structure feldspar ceramic combined with a proportion of polymer material consisting of UDMA and TEG-DMA ${ }^{(33)}$. Additionally, material with lower modulus of elasticity and flexural strength provided lower fracture resistance, (Table 1). ${ }^{(25)}$ However, its lower modulus of elasticity made it a suitable material for implant supported restorations..$^{(53-55)}$ 
The second hypothesis of the present study which stated that the abutment type would not affect the fracture resistance of the tested all ceramic crowns was rejected. The results showed that crowns cemented on custom made zirconia abutments recorded statistically significantly higher mean fracture resistance values than those cemented on ready made ones regardless of the crown material, (Table 4).A possible explanation of this finding may be related to the difference in the finish line pattern between the abutments, the scalloped pattern of the ready made abutments led to occluso-cervical variations in the finish line location which subsequently reduced the strength of the all ceramic crown as confirmed previously. ${ }^{(64)}$ However, identical occluso-cervical locations of the finish on all axial surfaces of the custom made abutment used in this study increases the all ceramic crown strength as reported in earlier study. ${ }^{(64)}$

Furthermore, the effect of the abutment on the fracture resistance of all ceramic implant supported restoration was previously documented in the

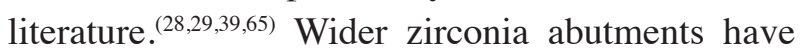
higher fracture resistance than narrower ones as mentioned by many authors. (66,67) Additionally, Schepke et al ${ }^{(12)}$ mentioned that stock abutments have a naturally smaller retention surface than the customized ones. Therefore, the higher fracture resistance of all ceramic crowns cemented on custom made abutments in this study may be linked to the abutment size, as the custom made abutment used is wider mesio-distally and bucco-lingually than the ready made abutments.

Associated with the values of fracture resistance, it is also important to analyze the types of fractures in each experimental group. This is not only because the result of the fracture resistance ensures a material is ideal for implant restoration, but also because the result will show what kind of failure will occur, that is, if the prognosis is favorable or not. Most of the crowns in the present study fractured or cracked with cohesive failures in the ceramic, mesiodistally dividing the crown into buccal and palatal parts, although the abutment remained intact. Usually one part remained attached to the abutment, similar to the findings in previous studies. ${ }^{(22,68)}$ This type of failure was shown with the steel ball of the universal testing machine that was adapted to the buccal and palatal cuspal inclines of the crown. The load applied on the crown favored the external displacement of the buccal and palatal cusps, with a tension concentration in the top of the abutment and a fracture line in the mesiodistal direction. ${ }^{(22)}$

Similar to the findings of Stona et al ${ }^{(22)}$ as well as Schepke and colleagues ${ }^{(12)}$ most of the cement remnants were predominantly attached to the crown fragments and not to the underlying ready or custom made zirconia abutments of this study.Its believed that this finding may be related to the fact that no surface treatment was done to the abutments similar to other study ${ }^{(22)}$ as it is not recommended by the ready made abutment manufacturer.

The fracture resistance results of all ceramic crowns cemented on different types of abutments in the present study were better than the normal masticatory forces applied on premolar teeth, which correspond to values of $300 \mathrm{~N}$ to $400 \mathrm{~N} .^{(69-71)}$ This indicates the suitability of the tested machinable all ceramic materials and abutments for the implant supported monolithic posterior crowns.

The limitations of this study include being an in vitro investigation which cannot reproduce all clinical parameters. However, they may provide an insight into material characteristics, use, function and performance during a short time under reproduced and standardized conditions. Also, the use of static instead of cyclic loading which would better simulate the clinical situation. The present study sets the foundation for further research that should include clinical trails to confirm the performance of this materials as a choice for monolithic posterior implant supported single restorations. 


\section{CONCLUSIONS}

All tested implant-supported all-ceramic monolithic posterior crowns cemented on ready and custom made zirconia abutments had the potential to withstand the physiologic occlusal forces in the premolar region with the superiority of the zirconia crowns cemented on custom made zirconia abutments.

\section{REFERANCES}

1. Jung R.E., Pjetursson B.E., Glauser R., Zembic A., Zwahlen M., Lang N.P. A systematic review of the 5-year survival and complication rates of implant-supported single crowns. Clin Oral Implants Res 2008;19: 119-130.

2. Jung R.E.,Zembic A., Pjetursson B.E.,Zwahlen M., Thoma D. Systematic review of the survival rate and the incidence of biological, technical and esthetic complications of single crowns on implants reported in longitudinal studies with a mean follow-up of 5 years. Clin Oral Implants Res 2012; 23(6): 2-21

3. Andersson B., Odman P., Lindvall A.M., Lithner B. Singletooth restorations supported by osseointegrated implants: results and experiences from a prospective study after 2 to 3 years. Int J Oral Maxillofac Implants 1995; 10: 702-711.

4. Park S.E., Da Silva J.D., Weber H.P., Ishikawa Nagai S. Optical phenomenon of periimplant soft tissue. Part i. Spectrophotometric assessment of natural tooth gingiva and periimplant mucosa. Clin Oral Implants Res 2007;18: 569-574

5. Jung R.E., Holderegger C., Sailer I., Khraisat A., Suter A., Hammerle C.H. The effect of all-ceramic and porcelainfused-to-metal restorations on marginal peri-implant soft tissue color: a randomized controlled clinical trial. Int J Periodontics Restorative Dent 2008;28: 357-365.

6. Glauser R, Sailer I, Wohlwend A, Studer S, Schibli M, Scharer P. Experimental zirconia abutments for implantsupported single-tooth restorations in esthetically demanding regions: 4-year results of a prospective clinical study. Int J Prosthodont 2004;17:285-90.

7. Binon PP. Implants and components: entering the new millennium. Int J Oral Maxillofac Implants 2000;15:76-94.

8. Nakamura K,Kanno T,Milleding P,Örtengren U.Zirconia as a dental implant abutment material:A systematic review. Int J Prosthodont 2010;23:299-309.
9. Velázquez-Cayón R, Vaquero-Aguilar C, Torres-Lagares D, Jiménez-Melendo M, Gutiérrez-Pérez J. Mechanical resistance of zirconium implant abutments: A review of the literature. Med Oral Patol Oral Cir Bucal. 2012 Mar 1;17 (2):e246-250.

10. Abduo J, Lyons K. Rationale for the use of CAD/CAM technology in implant prosthodontics. Int J Dent. 2013; 2013: 768121 .

11. Mühlemann S, Truninger TC, Stawarczyk B, Hämmerle $\mathrm{CH}$, Sailer I. Bending moments of zirconia and titanium implant abutments supporting all-ceramic crowns after aging. Clin Oral Impl Res. 2014; 25:74-81.

12. Schepke U, Meijer HJ, Vermeulen KM, Raghoebar GM, Cune MS. Clinical bonding of resin nano ceramic restorations to zirconia abutments: a case series within a randomized clinical trial. Clin Implant Dent Relat Res 2016;18(5) :984-992.

13. Guilherme NM, Chung KH, Flinn BD, Zheng C, Raigrodski AJ. Assessment of reliability of CAD-CAM tooth-colored implant custom abutments. J Prosthet Dent. 2016; 116(2):206-213.

14. Nogueira LB, Moura CD, Francischone CE, Valente VS Alencar SM, Moura WL, Soares Martins GA. Fracture strength of implant-supported ceramic crowns with customized zirconia abutments: screw retained vs. cement retained. J Prosthodont. 2016 Jan;25(1):49-53.

15. Sellers K, Powers J M, Kiat-amnuay S. Retentive strength of implant - supported CAD-CAM lithium disilicate crowns on zirconia custom abutments using 6 different cements. J Prosthet Dent 2016 DOI: 10.1016/j.prosdent.2016.06.014.

16. Kapos T, Evans C. CAD/CAM technology for implant abutments, crowns, and superstructures. Int $\mathrm{J}$ Oral Maxillofac Implants. 2014;29 (1):117-136.

17. Kurbad A, Kurbad S. CAD/CAM -based implant abutments made of Lithium Disilicate. Int J Comput Dent 2013;16(2):125-141

18. Parpaiola A, Norton MR, Cecchinato D, et al. Virtual abutment design: a concept for delivery of CAD/CAM customized abutments- report of a retrospective cohort. Int J Periodontics Restorative Dent 2013;33(1):51-58.

19. Kohal R J, Att W, Chle M, Butz F. Ceramic abutments and ceramic oral implants. An update. Periodontology 2000. 2008;47: 224-243. 
20. Kim J H, Lee S J, Park J S, Ryu J J. Fracture Load of monolithic CAD/CAM Lithium Disilicate ceramic crowns and veneered zirconia crowns as a posterior implant restoration. Implant Dent 2013;22:66-70.

21. Kok Pd, Kleverlaan C J, Jager N d, Kuijs R,. Feilzer A J. Mechanical performance of implant-supported posterior crowns. J prosthet dentistry 2015; 114( 1) : 59-66.

22. Stona D, Burnett LH Jr, Mota EG, Spohr AM. Fracture resistance of computer-aided design and computeraided manufacturing ceramic crowns cemented on solid abutments. J Am Dent Assoc. 2015;146(7):501-507.

23. Rohr N, Coldea A, Zitzmann NU, Fischer J. Loading capacity of zirconia implant supported hybrid ceramic crowns. Dent Mater. 2015;31(12):e279-288.

24. Kurbad A. Final restoration of implants with a hybrid ceramic superstructure. Int J Comput Dent. 2016; 19(3):257-279.

25. Rosentritt M, Hahnel S, Engelhardt F, Behr M, Preis V. In vitro performance and fracture resistance of CAD/CAMfabricated implant supported molar crowns. Clin Oral Investig. 2016 DOI:10.1007/s00784-016-1898-9.

26. Weyhrauch M, Igiel Ch, Scheller H, Weibrich G, Lehmann K M. Fracture strength of monolithic all-ceramic crowns on titanium implant abutments. Int $\mathrm{J}$ Oral Maxillofac Implants 2016; 31( 2 ): 304-309.

27. Oderich E, Boff LL, Cardoso AC, Magne P. Fatigue resistance and failure mode of adhesively restored custom implant zirconia abutments. Clin Oral Implants Res. 2012;23(12):1360-1368.

28. Att W, Kurun S, Gerds T, Strub JR. Fracture resistance of single-tooth implant-supported all-ceramic restorations: an in vitro study. J Prosthet Dent. 2006;95(2):111-116.

29. Mitsias M1, Koutayas SO, Wolfart S, Kern M. Influence of zirconia abutment preparation on the fracture strength of single implant lithium disilicate crowns after chewing simulation. Clin Oral Implants Res. 2014;25(6):675-682.

30. Joda T, Brägger U. Complete digital workflow for the production of implant-supported single-unit monolithic crowns. Clin Oral Implants Res.2014;25(1):1304-1306

31. Denry I, Kelly J R. Emerging ceramic-based materials for Dentistry. J Dent Res 2014;93(12):1235-1242

32. McLean JW.Ceramics in clinical dentistry.Br Dent J 1988;164 (6):310.
33. Kurbad A, Kurbad S . A new, hybrid material for minimally invasive restorations in clinical use. Int $\mathrm{J}$ Comput Dent 2013; 16(1):69-79.

34. Coldea A1, Swain MV, Thiel N. Mechanical properties of polymer-infiltrated-ceramic-network materials. Dent Mater. 2013; 29(4):419-426.

35. Magne P1, Silva M, Oderich E, Boff LL, Enciso R. Damping behavior of implant-supported restorations. Clin Oral Implants Res. 2013;24(2):143-148.

36. All-ceramic chairside preparation guide for IPS e.max. Ivoclar vivadent.

37. Zortuk M, Bolpaca P, Kilic K, Ozdemir E, Aguloglu S. Effects of Finger Pressure Applied By Dentists during Cementation of All-ceramic crowns. Eur J Dent 2010;4: 383-388.

38. Vásquez V, Ozcan M, Nishioka R, Souza R, Mesquita A, Pavanelli C. Mechanical and thermal cycling effects on the flexural strength of glass ceramics fused to titanium. Dent Mater J 2008; 27:7-15.

39. El-S'adany A F, Masoud G E, Kamel M S, Korsel A M.Fracture resistance of all ceramic crowns supported by zirconia and alumina versus titanium implant abutments . Tanta Dental J 2013; 10( 3) : 103-111.

40. Yildirim M, Fischer H, Marx R, Edelhoff D. In vivo fracture resistance of implant-supported all-ceramic restorations. J Prosthet Dent 2003; 90: 325-331.

41. Glauser R, Wohlwend A, Studer S. Application of zirconia abutments on single-tooth implants in the maxillary esthetic zone. A 6-year clinical and radiographic follow-up report. Applied Osseointegration Research 2004; 4: 41-45.

42. Zembic A, Sailer I, Jung RE, Hämmerle CH. Randomizedcontrolled clinical trial of customized zirconia and titanium implant abutments for single-tooth implants in canine and posterior regions: 3-year results. Clin Oral Implants Res. 2009;20(8):802-808.

43. Philipps RW. Science of dental materials. Philadelphia: WB Saunders Co; 1982:502-530.

44. Binon PP. The external hexagonal interface and screw-joint stability: a primer on threaded fasteners. Qintessence Dent Technol. 2000;23:91-105.

45. Brodbeck U. The ZiReal post: a new ceramic implant abutment. J Esthet Restor Dent. 2003;15:10-23

46. Strub JR, Butz F, Semsch R. Single-tooth replacement with a new zirconia titanium cylinder implant abutment: a case report. Quintessence Dent Technol. 2003;26:171-178. 
47. Sannino G, Gloria F, Ottria L, Barlattani A. Influence of finish line in the distribution of stress trough an all ceramic implant-supported crown. A 3D Finite Element Analysis. Oral Implantol 2009; 2(2): 14-27.

48. Nakamura T, Saito O, Fuyikawa J, Ishigaki S. Influence of abutment substrate and ceramic thickness on the colour of heat-pressed ceramic crowns. J Oral Rehabil 2002; 29:805-809.

49. Sailer I, Philipp A, Zembic A, Pjetursson B E, Hammerle C H F, Zwahlen M. A systematic review of the performance of ceramic and metal implant abutments supporting fixed implant reconstructions. Clin Oral Implants Res2009;20:4-31.

50. Gracis S, Thompson Van P, Ferencz J L, Silva N R F A, Bonfante E A. A New Classification System for AllCeramic and Ceramic-like Restorative Materials. Int J Prosthodont 2015; (28) 3, 227-235.

51. Santos MJ, Costa MD, Rubo JH, Pegoraro LF, Santos GC Jr. Current all-ceramic systems in dentistry: a review. Compend Contin Educ Dent. 2015;36(1):31-37.

52. Ueda K, Güth JF, Erdelt K, Stimmelmayr M, Kappert H, Beuer F. Light transmittance by a multi-coloured zirconia material. Dent Mater J. 2015;34(3):310-314.

53. Skalak R. Biomechanical considerations in osseointegrated prostheses. J Prosthet Dent 1983;49:843-848.

54. Branemark PI.Osseintegration and its experimental background.J Prosthet Dent 1983;50:399-410.

55. Menini M, Conserva E, Tealdo T, Bevilacqua M, Pera F, Signori A, Pera P. Shock absorption capacity of restorative materials for dental implant prostheses: an in vitro study. Int J Prosthodont. 2013;26(6):549-56.

56. Komine F, Blatz M B, Matsumura H. Current status of zirconia-based fixed restorations. J Oral Sci 2010; 52(4): 531-539.

57. Beuer F, Stimmelmayr M, Gueth JF, Edelhoff D, Naumann M. In vitro performance of full-contour zirconia single crowns. Dent Mater 2012;28:449-456.

58. Wolf D, Bindl A, Schmidlin PR, Lüthy H, Mörmann WH. Strength of CAD/CAM-generated esthetic ceramic molar implant crowns. Int J Oral Maxillofac Implants 2008;23(4):609-617.

59. Kelly JR. Clinically relevant approach to failure testing of all-ceramic restorations. J Prosthet Dent 1999;81:652-661 .
60. Scherrer SS, Denry IL, Wiskott HW, Belser UC. Effect of water exposure on the fracture toughness and flexure strength of a dental glass. Dent Mater 2001;17:367-371.

61. Christel P, Meunier A, Heller M, Torre JP, Peille CN. Mechanical properties and short-term in-vivo evaluation of yttrium-oxide-partially-stabilized zirconia. J Biomed Mater Res 1989;23:45-61.

62. Piconi C, Maccauro G. Zirconia as a ceramic biomaterial. Biomaterials 1999;20:1-25.

63. Ritter RG. Multifunctional uses of a novel ceramic-lithium disilicate. J Esthet Restor Dent. 2010;22(5):332-341.

64. Doyle MG, Goodacre CJ, Munoz CA, Andres CJ. The effect of tooth preparation design on the breaking strength of Dicor crowns:3. Int J Prosthodont 1990;3:327-340.

65. Joo H-S, Yang H-S, Park S-W, Kim H-S, Yun K-D, Ji M-K, Lim H-P. Influence of preparation depths on the fracture load of customized zirconia abutments with titanium insert.J Adv Prosthodont. 2015; 7(3): 183-190.

66. Shabanpour R, Mousavi N, Ghodsi S, Alikhasi M. Comparative Evaluation of Fracture Resistance and Mode of Failure of Zirconia and Titanium Abutments with Different Diameters. J Contemp Dent Pract. 2015 1;16(8):613-618.

67. Nguyen H Q, Tan K B, Nicholls J I. Load fatigue performance of implant-ceramic abutment combinations. Int J Oral Maxillofac Implants2009;24(4):636-646.

68. Bindl A, Richter B, Mörmann WH. Survival of ceramic computer aided design/manufacturing crowns bonded to preparations with reduced macro retention geometry. Int $\mathrm{J}$ Prosthodont. 2005;18(3):219-224.

69. DeLong R, Douglas WH. Development of an artificial oral environment for the testing of dental restoratives: bi-axial force and movement control. J Dent Res. 1983;62(1):32-36.

70. Tortopidis D, Lyons MF, Baxendale RH, Gilmour WH. The variability of bite force measurement between sessions, in different positions within the dental arch. J Oral Rehabil. 1998;25(9):681-668.

71. Fontijn-Tekamp F A, Slagter A P, Van Der Bilt A, Van 'T Hof M A, Witter D J, Kalk W, Jansen JA. Biting and chewing in overdentures, full dentures, and natural dentitions. J Dent Res 2000; 79(7): 1519-1524. 